\title{
Konsep Desain Lansekap Areal Selamat Datang Fakultas Pertanian Universitas Udayana Kampus Bukit Jimbaran, Bali
}

\author{
AULIA AKBAR ISMAIL HAMONANGAN ${ }^{1}$, SANG MADE SARWADANA ${ }^{1 *}$ \\ LURY SEVITA YUSIANA ${ }^{1}$ \\ 1. PS Agroekoteknologi, Fakultas Pertanian, Universitas Udayana, \\ Jl. PB. Sudirman Denpasar, 80232 Bali \\ *E-mail: sarwadana55@gmail.com
}

\section{ABSTRACT \\ Landscape Design Concept of Faculty of Agriculture Welcome Area in Udayana University Jimbaran Campus, Bali}

Campus is an area which multi-segment interactions will be taking place, the landscape situation has to manage to create a fine condition and gain good quality of education inside. As a front yard area which will be passed through by everybody who wants to come inside the campus welcome area has to raise any good impression and able to support the students requirement area to do their campus activities. This research has purpose to create a concept of landscape design of welcome area which has values of aesthetic, functional, and creating landscape identity of faculty of agriculture the University of Udayana. This researh has four steps: site measuring, inventaritation, analysis and syntesis, and creating the concepts. The concept of design is formal with Bali traditional arrangement. The concept will aplicate some principals of design such as balance, proportion, repetation, scale, and use shapes streinght and simetry. The concept of space create from Balinese local traditional wisdom the Tri Hita Karana (three source of happiness). The final products are concept plan and some drawings of 3D ilustration. Design concept with traditional Bali arragement wish to be aplicated by all of institution in the University of Udayana to create a unity of landscape which based on Bali local wishdom.

Keywords: bali, campus, landscape design, udayana, welcome area

\section{Pendahuluan}

Lansekap kampus sebaiknya dapat menciptakan lingkungan yang mendukung keberlangsungan proses belajar mengajar di dalamnya, seperti ruang berdiskusi, bersantai, membaca dan kegiatan lain yang berguna untuk menyerap dan mengembangkan ilmu yang didapatkan dalam perkuliahan. Lansekap kampus dapat digolongkan ke beberapa bagian, salah satunya adalah areal selamat datang. Areal selamat datang Fakultas Pertanian Universitas Udayana (FP Unud) merupakan areal 
pertama yang akan dilalui saat memasuki komplek kampus FP Unud, kondisi areal tersebut saat ini belum tertata rapi belum dapat menunjukkan identitas lansekap kampus yang ideal. Mahatvayudha (2012) menguraikan permasalahan dan kendala mengenai kenyamanan kampus FP Unud saat ini antara lain; kurangnya penataan pada ruang, kurangnya penataan jalur sirkulasi, serta kurangnya penataan vegetasi tanamannya.

\subsection{Rumusan Masalah}

Bagaimana konsep desain lansekap pada areal selamat datang FP Unud Bukit Jimbaran yang sesuai dengan konsep perancangan lansekap kampus, yang bernilai estetik, fungsional, dan dapat memperkuat identitas lansekap kampus tersebut.

\subsection{Tujuan Penelitian}

Menghasilkan konsep desain lansekap areal selamat datang kampus FP Unud Bukit Jimbaran yang bernilai estetik, fungsional, dan dapat memperkuat identitas lansekapnya.

\subsection{Manfaat Penelitian}

Penelitian ini diharapkan dapat bermanfaat dalam memberikan sumbangan ide alternatif terhadap desain lansekap areal selamat datang pada FP Unud, serta sebagai bahan masukan bagi pihak perancang taman dan pihak terkait lainnya untuk memberlakukan kebijakan mengenai pengembangan kawasan Universitas Udayana pada khususnya dan pada kawasan Bukit Jimbaran pada umumnya.

\subsection{Tinjauan Pustaka}

Simonds (1983) menjelaskan bahwa dalam lansekap karakter tapak yang menarik harus diciptakan atau dipertahankan sehingga semua elemen yang memiliki banyak variasi menjadi kesatuan yang harmonis. Lebih lanjut Simonds menjelaskan bahwa dalam mendesain sebuah lansekap terdapat sebuah prinsip, yaitu dengan mengeliminasi elemenelemen yang buruk dan menonjolkan elemen-elemen yang baik, karakter tapak yang menarik harus diciptakan atau dipertahankan sehingga semua elemen yang banyak variasinya akan menjadi kesatuan yang harmonis. Ingram (1991) menambahkan bahwa prinsip-prinsip desain merupakan perpaduan antara elemen-elemen desain yang tergabung dan saling berinteraksi dalam pembentukan suatu taman, yaitu: kesatuan, keseimbangan, peralihan, pemberian focal point, kesesuain, irama, pengulangan dan kesederhanaan.

\section{Metode Penelitian}

Metode yang digunakan dalam penelitian ini adalah metode analisis deskriptif kualitatif yang mengacu pada tahapan proses perancangan lengkap Simonds (1983). Proses perancangan dibagi ke dalam empat tahap, yaitu; persiapan awal, inventarisasi, analisis dan sintesis, dan pembuatan konsep. Skema tahapan penelitian dapat dilihat pada Gambar 1. 


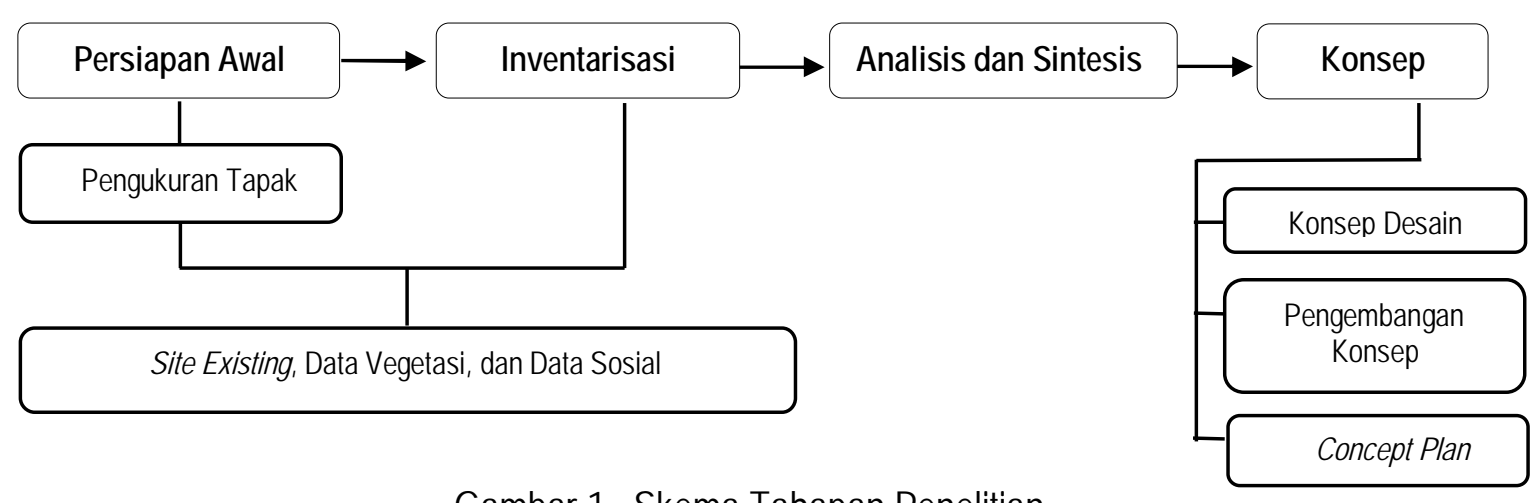

Gambar 1. Skema Tahapan Penelitian

\section{Hasil dan Pembahasan}

\subsection{Inventaris, Analisis, dan Sintesis}

\section{$3.1 .1 \mathrm{lklim}$}

Tabel 1. Data Iklim

\begin{tabular}{ll}
\hline \multicolumn{1}{c}{ Data } & \multicolumn{1}{c}{ Ukuran } \\
\hline Curah Hujan & $209,2(14$ hari/bulan) atau 101 - $150 \mathrm{~mm} /$ tahun \\
Suhu & Siang : $30-32{ }^{\circ} \mathrm{C}$ \\
& Malam : $22-29^{\circ} \mathrm{C}$ \\
Kelembaban & $43 \%$ \\
Lama Penyinaran Matahari & 8 jam 45 menit setiap hari \\
Kecepatan Angin & Siang : $10-23 \mathrm{~km} / \mathrm{jam}$ dari arah Timur, \\
& Malam : $11-25 \mathrm{~km} / \mathrm{jam}$ \\
\hline Sumber: Pemerintah Kabupaten Badung (2011)
\end{tabular}

\subsubsection{Lokasi dan batas tapak}

Berdasarkan pengukuran yang dilakukan di lapangan, areal selamat datang memiliki lahan seluas $5.600 \mathrm{~m}^{2}$. Tapak berbatasan langsung dengan areal perkuliahan kampus FP Unud di sebelah Timur, di sebelah Selatan berbatasan dengan perumahan warga (Pondok Mekar I), di sebelah Barat berbatasan dengan Jl. Raya Kampus Universitas Udayana, dan di sebelah Utara berbatasan dengan kampus Fakultas Peternakan Unud.

Tapak belum memiliki pagar pembatas, keadaan tersebut menyebabkan hewan ternak warga sekitar bisa masuk ke areal tapak dengan leluasa, sehingga dapat merusak vegetasi yang berada pada tapak, hal ini menyebabkan perlunya membuat pagar pembatas untuk menghalangi hewan ternak ternak tersebut memasuki areal tapak dan juga akan berfungsi meningkatkan kemanan areal parkir kendaraan bermotor yang berbatasan langsung dengan jalan raya.

\subsubsection{Topografi dan tanah}

Jenis tanah pada tapak adalah tanah Mediteran, jenis tanah tersebut memiliki karakteristik yang kurang subur karena bersifat basa dan kurang unsur hara, sehingga membutuhkan perlakuan ekstra terhadap pertumbuhan tanaman. Namun karakteristik tanah cukup potensial untuk digunakan sebagai pondasi konstruksi bangunan, karena 
tidak perlu untuk melakukan pengerasan lahan terlebih dahulu dan langsung dapat digunakan sebagai pondasi pada konstruksi bangunan yang akan dibuat.

\subsubsection{Aksesibilitas dan sirkulasi}

Areal selamat datang FP Unud memiliki dua gerbang masuk, gerbang Selatan dan gerbang Utara. Akses masuk yang bisa dimanfaatkan saat ini adalah gerbang Selatan, sedangkan gerbang Utara sedang dinonaktifkan karena berada pada jalan tikungan dan menanjak yang memiliki resiko yang tinggi terhadap kendaraan yang masuk dan keluar gerbang tersebut. Pengguna tapak pada umumnya menggunakan kendaraan pribadi (sepeda motor $80 \%$ dan mobil 3,6\%), dan yang lainnya menggunakan Bis Angkutan Umum lainnya berjalan kaki. Areal selamat datang FP Unud tidak memiliki jalur pedestrian, sehingga para pengguna menggunakan jalur kendaraan bermotor untuk berlalu lalang, kondisi tersebut dapat menggangu kenyamanan pejalan kaki karena cukup berbahaya bagi pejalan kaki.

\subsubsection{Fasilitas}

Fasilitas yang terdapat pada areal selamat datang FP Unud antara lain: areal persembahyangan, lapangan upacara, areal parkir, taman, planter, halte, dan fasilitas pendukung lainnya seperti papan nama, dan papan informasi. Kondisi fasilitas yang ada pada tapak saat ini berbeda-beda, ada yang masih dalam kondisi baik dan layak pakai dan ada yang perlu perbaikan. Selain itu jenis dan jumlah fasilitas pendukung yang ada masih kurang memadai. Penambahan fasilitas pendukung diperlukan seperti seperti lampu taman, penambahan keran air, papan pengumuman, dan kantin. Penambahan fasilitasfasilitas pendukung akan berfungsi meningkatkan kenyamanan pengguna tapak dan menghindari kegiatan-kegiatan vandalisme.

\subsubsection{Vegetasi}

Berdasarkan hasil pengamatan, tanaman-tanaman yang ada di beberapa areal terlihat kurang sesuai, seperti tanaman pengarah jalan yang belum seragam, tanaman semak yang terlalu beragam di pinggir lapangan upacara, dan jumlah tanaman peneduh yang sangat kurang memadai pada areal parkir. Selain itu tanaman-tanaman perdu dan semak yang ditanam pada taman gedung administrasi dan planter-planter pada tapak juga kurang dirawat, site eksisting dapat dilihat pada Gambar 2.

\subsubsection{Aspek Sosial}

Tapak digunakan oleh Civitas Akademika dari Fakultas Pertanian dan Jurusan IImu Komputer Fakultas Matematika dan Ilmu Pengetahuan Alam Universitas Udayana (Ilkom MIPA Unud. Areal selamat datang FP Unud merupakan areal yang dilalui pertama kalinya saat memasuki komplek kampus FP Unud, aktivitas yang terjadi pada tapak antara lain belajar, berkumpul, berdiskusi, bersantai, makan, menggunakan jaringan wi-fi kampus, dan sembahyang. 


\subsection{Konsep}

\subsubsection{Konsep Desain}

Konsep desain yang diterapkan adalah formal dengan tatanan tradisional Bali. Nilai formal diciptakan dengan menerapkan beberapa prinsip desain seperti prinsip keseimbangan, skala, dan proporsi. Konsep tradisional Bali diterapkan pada konsep ruang dan konsep vegetasi yang berlandaskan prinsip-prinsip Taman Gumi Banten.

\subsubsection{Konsep Ruang}

Ruang dibagi menjadi 3 bagian berdasarkan filosofi Tri Hita Karana (THK), yaitu: ruang Parahyangan, ruang Pawongan dan ruang Palemahan. Konsep THK digunakan sebagai penerapan kearifan lokal daerah Bali yang memiliki konsep pelestarian keanekaragaman budaya dan lingkungan di tengah perkembangan zaman yang bersifat moderenisasi dan hegemonisasi. Ruang Parahyangan merupakan penerapan hubungan manusia dengan Tuhan, diterapkan dengan pengadaan ruang persembahyangan bagi umat Hindu. Ruang Pawongan merupakan penerapan hubungan manusia dengan manusia (sosial), digunakan untuk berinteraksi satu sama lain seperti aktivitas diskusi, makan, membaca, bersantai, dan memarkirkan kendaraan. Ruang Palemahan adalah penerapan hubungan manusia dengan alam semesta, ruang ini merupakan ruang tempat berinteraksi manusia dan lingkungan.

\subsubsection{Konsep sirkulasi}

Berdasarkan penggunaannya sirkulasi dibagi menjadi tiga tipe, yaitu sirkulasi primer, sirkulasi sekunder, dan sirkulasi tersier. Sirkulasi primer dilalui oleh mobil, sepeda motor, sepeda, dan pejalan kaki, sirkulasi sekunder dilalui khusus sepeda motor, dan sirkulasi tersier khusus pejalan kaki. Ketiga jalur sirkulasi tersebut memiliki titik konflik sirkulasi, yaitu jalur transisi.

\subsubsection{Konsep Vegetasi}

Tanaman yang digunakan memiliki konsep Taman Gumi Banten, yaitu menggunakan tanaman-tanaman Upakara. Konsep ini menjadi penciri identitas kedaerahan pada konsep desain yang menegaskan bahwa, pola masyarakatnya (masyarakat Hindu Bali) tidak pernah terlepas dari ritual kegiatan upacara atau ber-yadnya sebagai upaya meningkatkan kesejahteraan umat manusia.

Penempatan tanaman ditempatkan berdasarkan kriteria tanamannya, pada ruang Parahyangan ditanam tanaman yang memiliki aura paling dingin karena diyakini sebagai tanaman kesayangan para dewi dan juga tanaman-tanaman yang berbau harum dan memiliki bunga, di ruang Pawongan ditanam tanaman-tanaman yang dapat dikonsumsi atau dijadikan obat oleh manusia, dan di ruang Palemahan ditanam tanaman-tanaman yang bisa difungsikan sebagai makanan ternak.

Penempatan tanamannya juga menggunakan konsep Catur Desa, konsep ini menggunakan pola Asta Dala (arah mata angin) dalam menentukan warna tanaman yang digunakan. Di Utara ditanam tanaman yang berwarna hijau tua sebagai representasi Dewa Wisnu, di Selatan berwarna merah sebagai representasi Dewa Brahma, di Barat berwarna 
kuning sebagai representasi Dewa Mahadewa, dan di Timur berwarna putih sebagai representasi Dewa Iswara (Negara, 2008).

Berdasarkan fungsi ekologisnya, tanaman yang digunakan dibagi menjadi vegetasi peneduh, vegetasi estetik, dan vegetasi pengarah jalan, dan vegetasi penutup tanah. Jenis dan fungsi tanaman yang digunakan dapat dilihat pada Tabel 2 berikut ini, dan penempatannya pada Gambar 3.

Tabel 2. Jenis dan Fungsi Tanaman yang Digunakan

\begin{tabular}{|c|c|c|c|c|}
\hline \multirow{2}{*}{ Fungsi } & \multicolumn{3}{|c|}{$\mathrm{Nama}$} & \multirow{2}{*}{ Jumlah } \\
\hline & Indonesia & Lokal/Bali & Ilmiah & \\
\hline Vegetasi & Dewadaru & Nagasari & Mesua ferrea & 2 \\
\hline \multirow[t]{2}{*}{ Penaung } & Mimba & Intaran & Azadirachta indica & 50 \\
\hline & Dadap Merah & Dapdap Wong & Eritherina crista-galli & 7 \\
\hline Vegetasi & Kelapa Gading & Nyuh Gading & Cocos nucifera ceburnea & 4 \\
\hline Estetik & Kamboja & Jepun Petak & Plumeria alba & 6 \\
\hline $\begin{array}{l}\text { Pengarah } \\
\text { Jalan }\end{array}$ & Dadap Merah & Dapdap Wong & Eritherina crista-galli & 22 \\
\hline Penutup & Bunga Landak & Landep & Barleria prionitis & - \\
\hline Tanah & Rumput Manila & Padang Kawat & Zoysia matrella Mer & - \\
\hline
\end{tabular}

\subsection{Concept Plan}

Concept plan merupakan aplikasi konsep desain yang digambarkan dengan produk block plan dan site plan dan selanjutnya dijabarkan dengan penjelasan beberapa areal secara spesifik dengan gambar ilustrasi. Block plan adalah komposit dari konsep ruang, konsep sirkulasi, dan konsep vegetasi yang digambarkan dalam bentuk denah. Konsep ini merupakan hasil perencanaan yang dibuat sebagai kebutuhan desain berdasarkan analisis dan sintesis yang telah dilakukan. Site plan merupakan gambar final dari konsep desain yang diterapkan, Site plan berisi data lengkap mengenai penggunaan elemen keras dan elemen lunak yang digunakan. Site plan konsep desain lansekap kampus FP Unud dapat dilihat pada Gambar 3. 


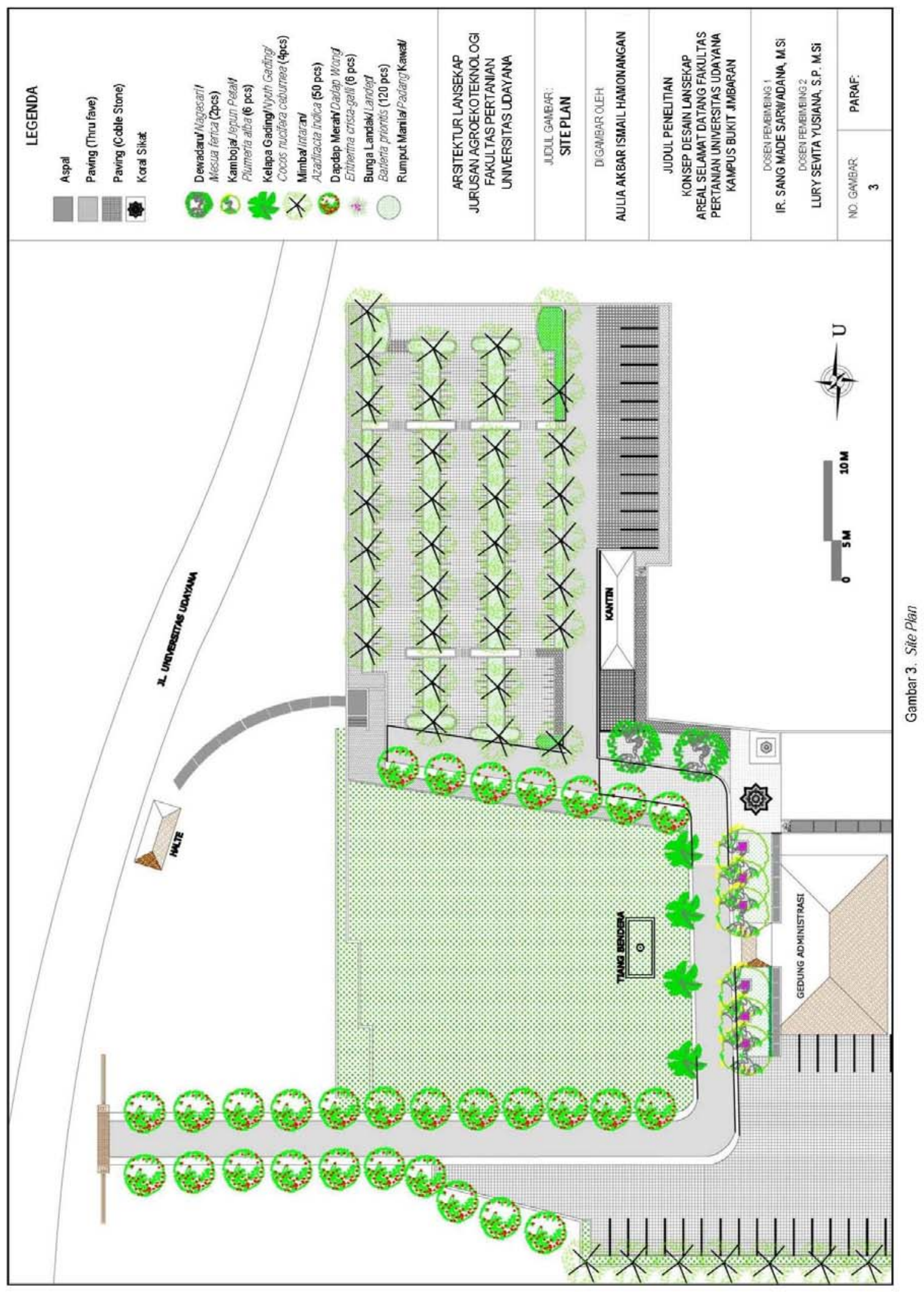




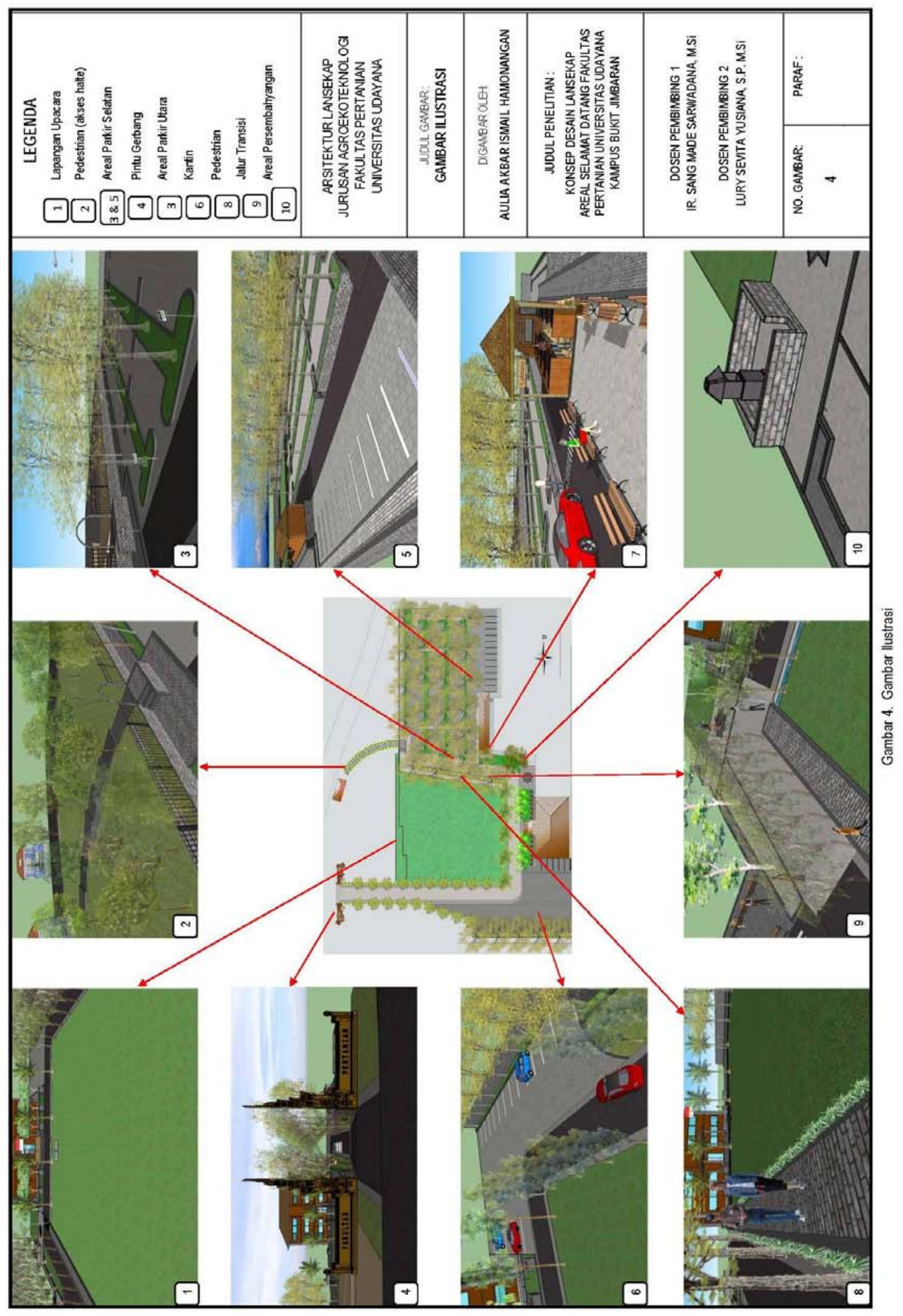




\section{Simpulan dan Saran}

Konsep desain pada areal selamat datang FP Unud adalah formal dengan tatanan tradisional Bali, konsep tersebut telah sesuai dengan tujuan penelitiannya, yaitu menciptakan lansekap kampus yang estetik, fungsional, dan dapat memperkuat identitas lansekap kampus. Nilai fungsional didapatkan dari penerapan konsep ruang yang dibagi berdasarkan fungsinya secara spesifik, yaitu ruang Parahyangan sebagai penerapan ruang interaksi manusia dengan Tuhan, ruang Pawongan sebagai ruang interaksi antar manusia, dan ruang Palemahan sebagai ruang interaksi manusia dan lingkungan. Nilai estetik didapatkan dari konsep formal yang diterapkan dari prinsip desain keseimbangan, kesatuan, repetisi, dan peletakan focal point, dan juga penggunaan pola-pola simetris pada perencanaan konsepnya. Penguatan identitas kampus didapatkan dari penerapan nilai-nilai tradisional Bali, yaitu penerapan filosofi Tri Hita Karana terhadap pembagian ruang dan penggunaan tanaman Upakara pada konsep vegetasinya.

Perancangan lansekap yang berlandaskan nilai-nilai tradisional Bali harus tetap dipertahankan untuk mempertahankan kearifan lokal Bali di bidang arsitektur, khususnya di tempat-tempat umum seperti lembaga pemerintahan, lembaga pendidikan, lembaga pelayanan masyarakat. Konsep desain lansekap yang menggunakan tatanan tradisional Bali diharapkan dapat diterapkan di semua lembaga di Universitas Udayana, sehingga berperan dalam menjaga kelestarian bidang arsitektur yang berlandaskan nilai tradisional lokal Bali.

\section{Daftar Pustaka}

Negara, I Gede Oka Surya. 2008. Penataan Tari "Dewata Nawa Sanga". Fakultas Seni Pertunjukan, Institut Seni Indonesia. Denpasar, Bali.

Ingram, Dwayne L. 1991. Basic Principles of Landscape Design. Institute of Food and Agricultural Sciences, The University of Florida, USA

Pemerintah Kabupaten Badung. 2011. Badung Dalam Angka 2011. Badung, Bali.

Simonds, J. O. 1983. Landscape Architecture: A Manual Site Planning and Design. McGraw-Hill Book Co. Inc, New York. 